\title{
Yiyecek ve İçecek İșletmelerinde Talep Tahmini: Yapay Sinir Ağları ve Regresyon Yöntemleriyle Bir Karşılaştırma
}

\author{
Oğuzhan Sönmez ${ }^{1}$, Kenan Zengin ${ }^{2}$ \\ ${ }^{1}$ Tokat GaziOsmanpaşa Üniversitesi, Reşadiye Meslek Yüksekokulu, Bilgisayar Teknolojileri Bölümü, Tokat, Türkiye (ORCID: 0000-0003-4456-7036) \\ ${ }^{2}$ Tokat GaziOsmanpaşa Üniversitesi, Mühendislik Fakültesi, Bilgisayar Mühendisliği Bölümü, İstanbul, Türkiye (ORCID: 0000-0000-0000-0000)
}

(This publication has been presented orally at HORA congress.)

(First received 1 August 2019 and in final form 25 October 2019)

(DOI: 10.31590/ejosat.638104)

\begin{abstract}
ATIF/REFERENCE: Sönmez, O. \& Zengin, K. (2019). Yiyecek ve İçecek İşletmelerinde Talep Tahmini: Yapay Sinir Ağları ve
\end{abstract} Regresyon Yöntemleriyle Bir Karşlaştırma. European Journal of Science and Technology, (Special Issue), 302-308.

\section{Öz}

Günümüzde yiyecek - içecek sektörüne olan ilgi sürekli artış göstermektedir. Dolayısıyla pazarda artan rekabet, işletmelerin ayakta kalmaları için teknolojiyle uyumlu çalışmaları zorunlu kılmaktadır. İşletmeler müşterilerin taleplerini tahmin edebilirseler planlamalarını da ona göre yapacak ve fazla iş gücü ve maliyetten kurtulacaklardır. Doğru olarak yapılan tahminler işletmeye fayda sağlayacak ve gerekli tedbirleri alacaklardır. Çalışmada Tokat bölgesinde faaliyet gösteren bir yiyecek-içecek işletmesinin verileri kullanılmıştır. Bu işletmenin satış tahmini için yapay sinir ağları ve çoklu regresyon modelleri kullanılarak günlük satışını tahmin edip ve iki modelin karşılaştırılması yapılmıştır. İlk çalışma matlab ortamında yapay sinir ağları aracı olan nntool kullanılmıştır. Veriler 2018 yıııın ilk 6 ayını içeren 150 satırdan oluşmaktadır ve \%70 eğitim \%30 ise test için kullanılmıştır. Yapay sinir ağımız 8 girişli tek gizli katmanlı ve 8 nöronlu tek çıkışlı bir modelden oluşmaktadır. Eğitim fonksiyonu olarak Levenberg-Marquard Algoritması(trainlm) ve aktivasyon fonksiyonu olarak ise tansig fonksiyonu kullanılmıştır. Modelimizde test $\mathrm{R}$ oranı $\% 95,77$ çıkmıştır. İkinci uygulamamızı anaconda platformunda, spyder ide sini kullanarak python programlama dilliyle geliştirdik. Uygulamada yine aynı parametreleri kullanarak çoklu regsesyon modeli uygularak yaptı̆ı̆ıız uygulamada ise doğruluk oranımız \%91,3 çıkmıştır. Burada kullandığımız parametreleri en küçük kareler yöntemiyle incelediğimizde işletmenin talep tahminini talep tahmininde haftanın günleri ve sıcaklığın yüksek değerde etkilemediğini görmekteyiz. Dolayısıyla çok ekstrem bir gün değilse veya havanın sıcak-soğuk olması işletmenin satışlarına pozitif -negatif yönde bir etki yapmamaktadır. Her iki modelde başarı oranların yüksek olması talep tahmininde yapay sinir ağları ve çoklu regresyon kullanımının pozitif etkisini gözler önüne sermektedir. Yapay sinir ağlarıyla geliştirdiğimiz model çoklu regresyon modeline göre daha başarılı olduğu gözlemlenmiştir. İşletme bulduğumuz sonuçlara göre planlamasını yaparak belirgin parametrelere daha fazla ağırlık verirse cirosunda artış görecektir.

\section{Demand Forecasting in Food and Beverage Enterprises: A Comparison via Artificial Neural Networks and Regression Methods}

\begin{abstract}
Today, interest in food and beverage sector is constantly increasing. Therefore, increasing competition in the market necessitates technology-compatible works in order to survive. If businesses can anticipate customers' demands, they will make their plans accordingly and avoid excessive labor and cost. Accurate estimates will benefit the enterprise and take the necessary measures. In this study, data of a food and beverage company operating in Tokat region was used. To estimate the sales of this enterprise by using artificial neural networks and multiple regression models, the daily sales are estimated and compared between the two models. In the first study, nntool, an artificial neural network tool, was used in the matlab environment. The data consisted of 150 lines including the first 6 months of 2018 and $70 \%$ of the training was used for $30 \%$ of the test. Our artificial neural network consists of a single-layered model with 8 http://dergipark.gov.tr/ejosat


inputs and a single-output model with 8 neurons. Levenberg-Marquard Algorithm (trainlm) was used as training function and tansig function was used as activation function. In our model, the test $\mathrm{R}$ ratio was $95.77 \%$. We developed our second application on python programming language using spyder ide on anaconda platform. In the application, using multiple regression model using the same parameters, the accuracy rate was $91.3 \%$. When we examine the parameters we use here with the least squares method, we see that the demand forecast of the enterprise does not affect the days of the week and the temperature at high value in demand forecasting. Therefore, if it is not a very extreme day or the weather is hot-cold, it does not have a positive-negative effect on the sales of the enterprise. The high success rates of both models show the positive effect of using artificial neural networks and multiple regression in demand forecasting. The model we developed with artificial neural networks was more successful than the multiple regression model. According to the results we find, if the firm places more weight on certain parameters by planning, it will see an increase in turnover

\section{Keywords: Demand Forecasting, Artificial Neural Networks, Multiple Regression, Food and Beverage Enterprises}

\section{Giriş}

Yiyecek-içecek sektöründeki oyuncuların hızlı değişmesi işletmeleri hızlı ve yeni kararlar almasına yol açabilir. Alınacak kararlar işletmelerin gelecekte ayakta kalmaları ve satışlarını artırmalarına yönelik olmalıdır. Gelecek adına doğru tahminler işletmenin doğru pozisyon almasını sağlayacaktır. Tahmin değerleri ile gerçek değerler arasındaki ilişkiyi doğru okumak işletmeleri zarar etmelerini engelleyecektir.

Talep tahmini için geliştirilen nicel yöntemlere örnek olarak Yapay Sinir Ağları, Genetik Algoritmalar, Destek Vektör Makineleri, Hareketli Ortalamalar Yöntemi, Üstel Düzleştirme Yöntemi, Ekonometrik Modeller, Basit Regresyon Analizi, Çoklu Regresyon Analizi verilebilir (Karaatlı, Helvacıoğlu, Ömürbek ve Tokgöz, 2012). (Karaartlı vd., 2012)

$\mathrm{Bu}$ çalışmada işletmelerde günlük yiyecek talebini yapay sinir ağları kullanarak tahmin edebilen ve çoklu regresyon modeli kullanılarak talep tahmini ve karşılaştırma yapılmıştır. Çalışmanın amacı işletmelerin belli parametrelerde ne kadar satış yapabileceklerini tahmin ederek onların yeni aksiyonlar almalarını sağlamaktır. Çalışmayı diğer çalışmalardan ayıran özellik böyle bir çalışma yapılmamış olması. Gerçek verilerden oluşan çalışmada gerçeğe yakın değerler bulması çalışmanın önemini ortaya koymaktadır.

Es ve arkadaşları (2007) Türkiyenin net enerji talebini, Calp (2018) İşletmeler için personel yemek miktarı tahmini, Efendigil ve arkadaşı (2017) Havacılık sektöründe yolcu talep tahmini, Akdağ (2016) Diyarrbakır kent merkezi içme suyu talebini, Eren ve arkadaşı (2017) Perakende giyim sektöründe talep tahmini, Çuhadar ve arkadaşı (2005) Konaklama işletmelerinde doluluk oranı tahmini, Ulucan ve arkadaşı (2018) Konaklama işletmelerinde talep tahmini, Çuhadar ve arkadaşları (2009) Antalya iline yönelik dış turizm talebi tahmini, Başoğlu ve arkadaşı (2016) Kısa dönem elektrik talep tahmini, Yücesan ve arkadaşları (2018) Beyaz eşya sektörü için bir satış tahmini, Hamzaçebi ve arkadaşı (2004) Türkiyede uzun dönemli elektrik enerjisi tüketim tahminini için yapay sinir ağlarını kullanmışlardır. Karaca ve arkadaşı (2016) Elektrik tüketim talebini etkileyen faktörleri, Üstündaüğ ve arkadaşı (2018) Antalya bölgesinde otel oda fiyatlarının tahmini, Turanlı ve arkadaşı (2003) Turizm sektöründe talep tahmini, Özüdoğru ve arkadaşı (2015) sağlık sektöründe talep tahmin için regresyon yöntemini kullanmışlardır.

\section{Metaryal ve Yöntemler}

Çalışmanın bu kısmında Makine öğrenmesi ve Yapay sinir ağları (YSA) konuları kısaca açıklanmıştır. Verilerin elde edilmesi, gereksiz verilerin temizlenmesi ve verileri eğitim ve test olarak ikiye ayrılarak modelin oluşturulma aşamalarından bahsedilmiştir.

\subsection{Makine Öğrenmesi (Machine Learning)}

Makine öğrenmesi verilere matematiksel ve istatiksel işlemler uygulayarak tahminlerde bulunması için algoritmaların tasarım ve süreçlerini konu alan bilim dalıdır. Makine öğrenmesi bir probleme ait verileri problem için modelleyen algoritmalardır. Birçok makine öğrenmesi yöntemi geliştirilmiştir. Naive Bayes Sınıflandırıcı, K-en yakın komşu algoritması, destek vektör makinaları, karar ağaçları, lojistik regresyon analizi ve yapay sinir ağları. Makine öğrenmesi algoritmaları sayesinde aralarındaki ilişkilere karar veremediğimiz, göremediğimiz birçok sınıflandırma ve tahmin işlemlerini yapılabilmektedir.

\subsection{Yapay Sinir Ağları}

YSA, bir sinir hücresinden esinlenerek nöron yapısı göz önünde bulundurularak modellenen ve zamanla kendi kendine öğrenme yeteneği olan bir yöntemdir. YSA insan beyni gibi davranış değişikliği yoluyla yeni bilgiler üretebilme ve keşfedebilme gibi yetenekleri, herhangi bir yardım almadan kendiliğinden gelişen makine öğrenmesi yöntemidir. (Chehreh ve arkadaşları, 2008). Şekil 1'de görüldüğ̈̈ gibi YSA modeli giriş katmanı, gizli katman ve çıktı katmanından oluşmaktadır. Gizli katman sayısı ve nöron sayıları yapılan çalışmada denemeler sonucu tespit edilebilir. Giriş katmanından herhangi işlem yapılmadan geçen veriler gizli katman ve çıkış katmanında bağlantıların ağırlık değerleri oranında çarpılarak gele veriler toplanır ve transfer fonksiyonuna aktarılır (Yongjae ve arkadaşları, 2005). Çok katmanlı yapay sinir ağları sınıflandırma problemlerini çözmek için kullanılır. Sadece doğrusal problemlerin çözümünde tek nöron yeterli olabilir. 


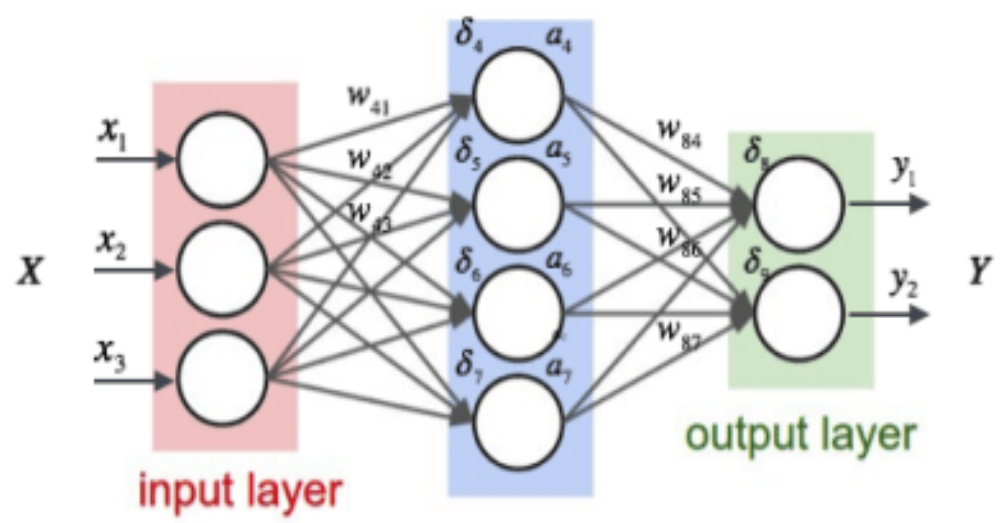

hidden layer

Şekil.1 Girişli tek gizli katmanlı 4 nöronlu 2 çıkışlı YSA

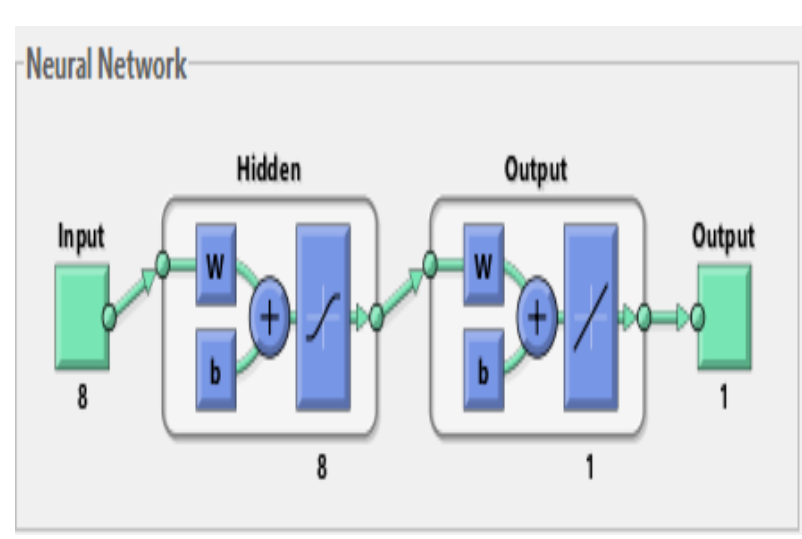

Şekil.2 Verilerimize uyguladı̆̆ımız YSA modeli

\subsection{Verilerin Elde Edilmesi}

Veriler 2018 yılında Tokattaki bir işletmenin veritabanından elde edinilmiş olup 150 günlük veriler mevcuttur. Veri seti 9 parametreden oluşmaktadır. Çalışmada işletmenin adı "XYZ" olarak geçmektedir

\subsection{Matlab Ortamında Modelin Oluşturulması}

Modeli oluştururken günlük talebi etkileyeceği düşünülen faktörler dikkate alınmıştır. Bu faktörler; Döner, Izgaralar, Kebaplar, Çorba, İçecek, Gerçekleşen hava sıcaklığı, müşterilerin satınalma gücünü etkileyen gerçekleşmiş efnlasyon verisi ve haftanın günleri (Pazartesi, Salı, Çarşamba, Perşembe, Cuma, Cumartesi, Pazar) olarak belirlenmiştir.

Çizelge 1. Verilerin Bir Kısmı

\begin{tabular}{|l|l|l|l|l|l|l|l|l|}
\hline GUNLER & ENFLASYON & HAVA & DONER & IZGARALAR & KEBAPLAR & CORBA & ICECEK & SATIS \\
\hline Pazartesi & 10.35 & 8 & 39 & 19 & 17 & 25 & 75 & 1878 \\
\hline Sali & 10.35 & 9 & 54 & 18 & 9 & 24 & 56 & 1886 \\
\hline Carsamba & 10.35 & 11 & 47 & 46 & 15 & 28 & 79 & 2686 \\
\hline Persembe & 10.35 & 11 & 44 & 29 & 20 & 16 & 52 & 1978 \\
\hline Cuma & 10.35 & 12 & 95 & 47 & 43 & 19 & 175 & 4090 \\
\hline Cumartesi & 10.35 & 11 & 62 & 34 & 18 & 14 & 119 & 2670 \\
\hline Pazar & 10.35 & 9 & 58 & 17 & 12 & 13 & 56 & 1816 \\
\hline Pazartesi & 10.35 & 7 & 37 & 21 & 13 & 15 & 46 & 1586 \\
\hline Sali & 10.35 & 7 & 64 & 30 & 11 & 15 & 73 & 2265 \\
\hline Carsamba & 10.35 & 8 & 68 & 27 & 22 & 24 & 91 & 2565 \\
\hline Persembe & 10.35 & 9 & 41 & 27 & 18 & 15 & 56 & 1922 \\
\hline Cuma & 10.35 & 7 & 32 & 37 & 20 & 15 & 64 & 1988 \\
\hline Cumartesi & 10.35 & 7 & 69 & 41 & 20 & 24 & 102 & 2871 \\
\hline Pazar & 10.35 & 5 & 107 & 32 & 23 & 58 & 126 & 4235 \\
\hline Pazartesi & 10.35 & 4 & 59 & 38 & 30 & 16 & 72 & 2921 \\
\hline Sali & 10.35 & 8 & 84 & 31 & 14 & 26 & 92 & 2895 \\
\hline Carsamba & 10.35 & 8 & 101 & 38 & 35 & 33 & 130 & 4191 \\
\hline Persembe & 10.35 & 9 & 58 & 23 & 12 & 16 & 60 & 2134 \\
\hline Cuma & 10.35 & 5 & 88 & 37 & 19 & 15 & 92 & 3038 \\
\hline Cumartesi & 10.35 & 9 & 60 & 23 & 24 & 15 & 104 & 2599 \\
\hline Pazar & 10.35 & 13 & 76 & 32 & 30 & 15 & 114 & 3121 \\
\hline
\end{tabular}

\subsubsection{Eğitim ve Test Süreci}


European Journal of Science and Technology

Matlab programında 150 adet gerçek veri içerisinden \% 70 eğitim \%30 kısmı test için ayrılmıştır. Eğitim ve test süreçlerine başlanmıştır. Modeli 20 kez uygulayıp ortalamasını alarak rastgele düşük veya yüksek oranlar yüzünden yanılma payını minimize ettik.

\subsubsection{Levenberg-Marquard Algoritması}

LM algoritması Dik iniş (Steepest descent) ve Newton algoritmalarından türetilmiştir. Ağırlık vektörü w, birim matris I, kombinasyon katsayısı $\mu$. Jacobian matrisini J (PxM)xN, hata vektörünü e $(P x M) x 1$ göstermektedir. Eğitim örnek sayısını P, çıkış sayısını M ve ağırlık sayısını $\mathrm{N}$ göstermektedir. $\mu$ ayarlanabilir bir parametredir.

$$
\Delta w=\left(J^{T} J+\mu l\right)^{-1} J^{T} e
$$

\subsubsection{Tansig Fonksiyonu}

Aktivasyon fonksiyonu için giriş-çıkış ifadesi (1) de fonksiyonun değişimi şekil 3'de verilmiştir. Fonksiyonun değişim aralığ [-1 1] aralığındadır ve toplam nöron girişe bağlı olarak fonksiyon lineer olmayaą bir değişim gösterir.

$$
a=\frac{2}{1+e^{(-2 n)}}-1
$$

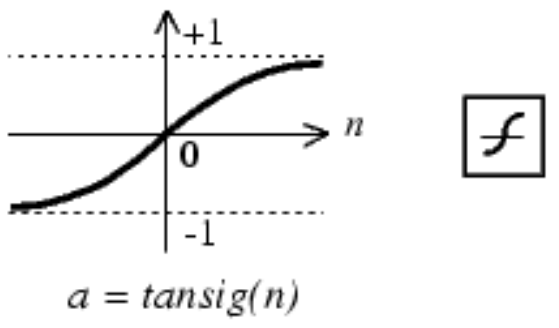

Şekil.3 Tangent-Sigmoid fonksiyonu giriş-çıkış ĕgrisi

\begin{tabular}{|c|c|c|c|c|c|c|c|}
\hline No & $\begin{array}{c}\text { Eğitim } \\
\text { Fonksiyonu }\end{array}$ & $\begin{array}{l}\text { Aktivasyon } \\
\text { Fonksiyonu }\end{array}$ & $\begin{array}{c}\text { Gizli } \\
\text { Katman }\end{array}$ & $\begin{array}{l}\text { Gizli katdaki } \\
\text { Nöron Sayıs }\end{array}$ & Eğitim R Oranı & $\begin{array}{c}\text { Doğruluk } R \\
\text { Oranı }\end{array}$ & Test R Oranı \\
\hline 1 & trainlm & tansig & 1 & 8 & 0.98456 & 0.98049 & 0.96041 \\
\hline 2 & trainlm & tansig & 1 & 8 & 0.98607 & 0.97487 & 0.97027 \\
\hline 4 & trainlm & tansig & 1 & 8 & 0.99022 & 0.96924 & 0.97543 \\
\hline 5 & trainlm & tansig & 1 & 8 & 0.9623 & 0.95429 & 0.96575 \\
\hline 6 & trainlm & tansig & 1 & 8 & 0.99059 & 0.9555 & 0.95383 \\
\hline 8 & trainlm & tansig & 1 & 8 & 0.99247 & 0.92508 & 0.97343 \\
\hline 9 & trainlm & tansig & 1 & 8 & 0.98988 & 0.96762 & 0.96845 \\
\hline 10 & trainlm & tansig & 1 & 8 & 0.98831 & 0.92483 & 0.93815 \\
\hline 11 & trainlm & tansig & 1 & 8 & 0.99272 & 0.975 & 0.965 \\
\hline 12 & trainlm & tansig & 1 & 8 & 0.98913 & 0.96833 & 0.98589 \\
\hline 13 & trainlm & tansig & 1 & 8 & 0.99244 & 0.97815 & 0.96123 \\
\hline 17 & trainlm & tansig & 1 & 8 & 0.98294 & 0.95817 & 0.96826 \\
\hline 18 & trainlm & tansig & 1 & 8 & 0.97669 & 0.98153 & 0.96781 \\
\hline 19 & trainlm & tansig & 1 & 8 & 0.96956 & 0.96775 & 0.98283 \\
\hline 20 & trainlm & tansig & 1 & 8 & 0.99192 & 0.94121 & 0.97122 \\
\hline Ortalama & & & & & 0.985462 & 0.962219 & 0.966286 \\
\hline
\end{tabular}

Çizelge 2. Performans Sonuçları

Çizelge 2 incelendiğinde uygulanan foknsiyonlar, katman sayısı, nöron sayıları ve bunlara karşılık eğitim, test ve doğruluk oranları görülmektedir. Veriler eğitildikten sonra denemeler sonucunda modelin eğitim-test değerlerine bir örnek Şekil 4'de verilmiştir. Eğitim R oranı ile test doğruluk oranı arasındaki fark çok yüksek olmadığı için sistemin herhangi bir ezberleme yapmadığınıda görmekteyiz. Test R oranı \%96,628 olarak karşımıza çıkmaktadır bu sonuç modelin verimli çalıştığını gösteriyor diyebiliriz. 


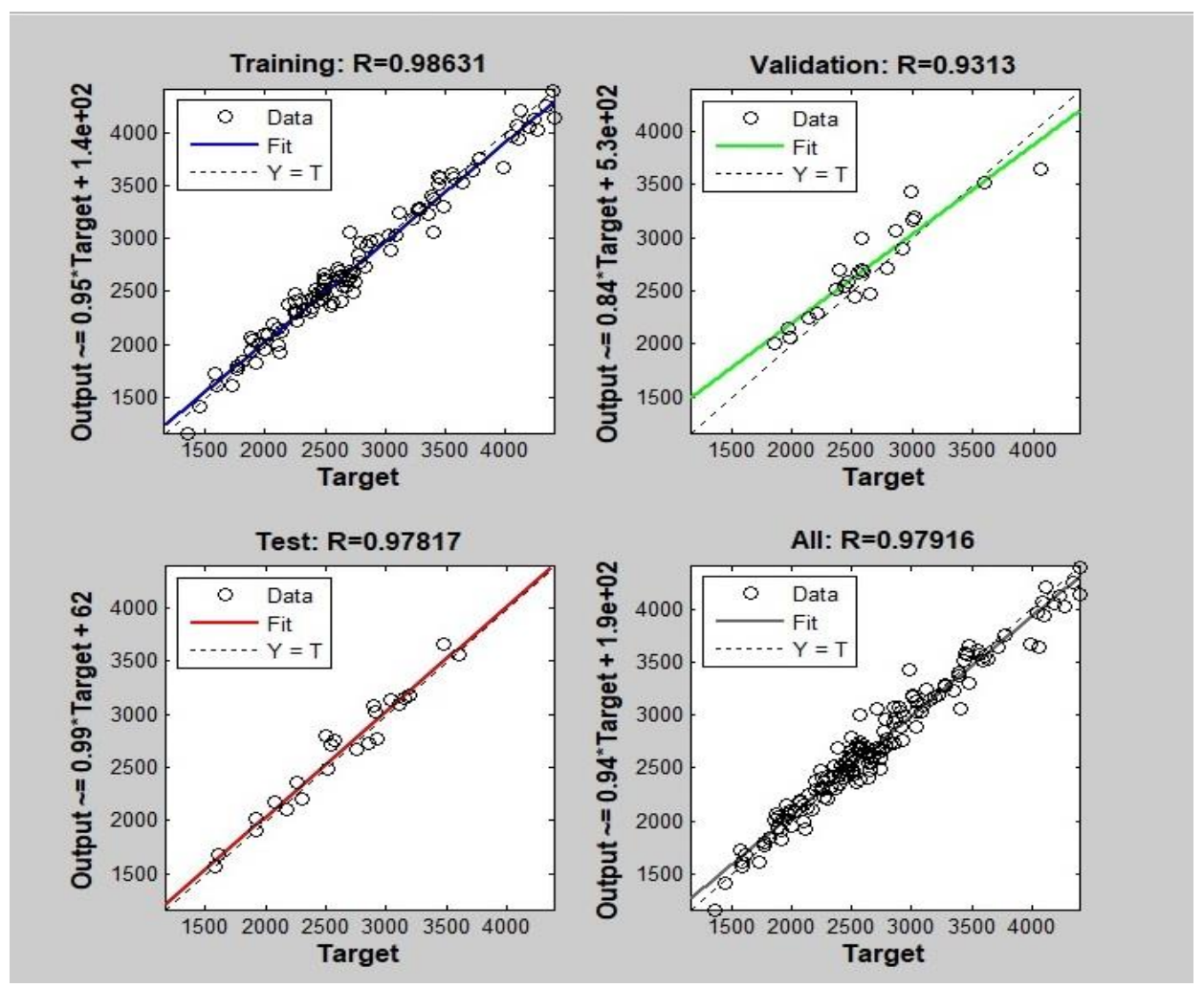

Şekil.4 Modelin Eğitim ve Test $R$ değeleri

\subsection{Python Ortamında Modelin Oluşturulması}

Çizelge 1'de bulunan veriler python programına data dosyası import edildi.

\subsubsection{Verilerin Eğitim ve Test Süreci}

Python programlama dilinde verilerin \%70 eğitim \%30 test verisi olarak sisteme dahil edilmişstir.

\subsubsection{Pandas Kütüphanesi}

Pandas python programlama dili için yüksek performanslı, kullanımı kolay veri yapıları ve veri analiz araçları sağlayan açık kaynaklı bir BSD lisanslı kütüphanedir. Csv ve text dosyalarını açmaya ve içerisinde bulunan verileri okuyarak istenen sonuca kolayca ulaşmak için kullanılmaktadır.

\subsubsection{Numpy Kütüphanesi}

NumPy (Numerical Python) bilimsel hesaplamaları hızlı bir şekilde yapmamızı sağlayan bir matematik kütüphanesidir. Numpy'ın temelini numpy dizileri oluşturur. Numpy dizileri python listelerine benzer fakat hız ve işlevsellik açısından python listelerinden daha kullanışıdır. Ayrıca python listelerinden farklı olarak Numpy dizileri homojen yapıda olmalıdır yani dizi içindeki tüm elemanlar aynı veri tipinden olmalıdır. (Durna, 2019).

\subsubsection{Sicikit-learn Kütüphanesi}

Scikit-learn yapay öğrenme alanında en yaygın olarak kullanılan kütüphanelerden biri. Doğrusal regresyon, lojistik regresyon, karar ağaçları, rastgele orman gibi birçok temel yöntemi içeren bu kütüphanedir. (Yüceoğlu, 2019)

\subsection{6 Çoklu Regresyon}


European Journal of Science and Technology

Çoklu regresyon bir adet bağımlı değişken ve birden fazla bağımsız değiş̧enin bir arada bulunduğu modeldir. Gerçek dünyada, tüm verileri anlamlı bir şekilde tanımlayan doğrusal fonksiyonlar bulunmayabilir, bazı durumlarda veri kümemizi eğri bir fonksiyon ile tanımlayabiliriz (Ulgen, 2019)

$\mathrm{Y}=\mathrm{b}_{1}+\mathrm{b}_{2} \mathrm{X}_{2}+\mathrm{b}_{3} \mathrm{X}_{3}+\ldots+\mathrm{b}_{\mathrm{k}} \mathrm{X}_{\mathrm{k}}+\mathrm{u}$

\subsubsection{En Küçük Kareler Yöntemi}

Regresyon çözümlemesinde amaç gerçek Y'ye(sonuca) olabildiğince yakın değerler veren katsayı tahminleri bulmaktır. Şekil 5'de modelin grafiği bulunmaktadır.

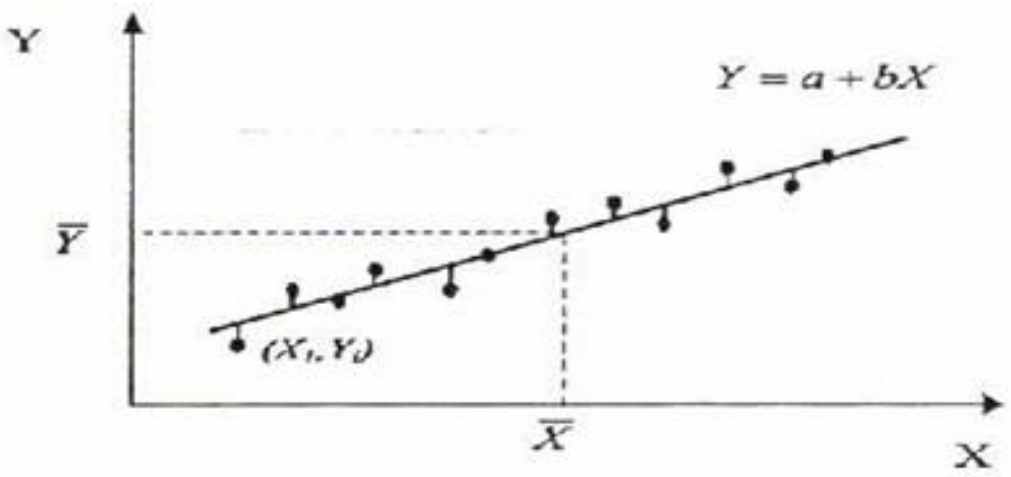

Şekil.5 En Küçük Kareler Yöntemi

\section{IPython console}

$\square$ Console $1 / \mathrm{A} \mathbb{X}$

[ 0.0 .0 28. 79. ]

OLS Regression Results

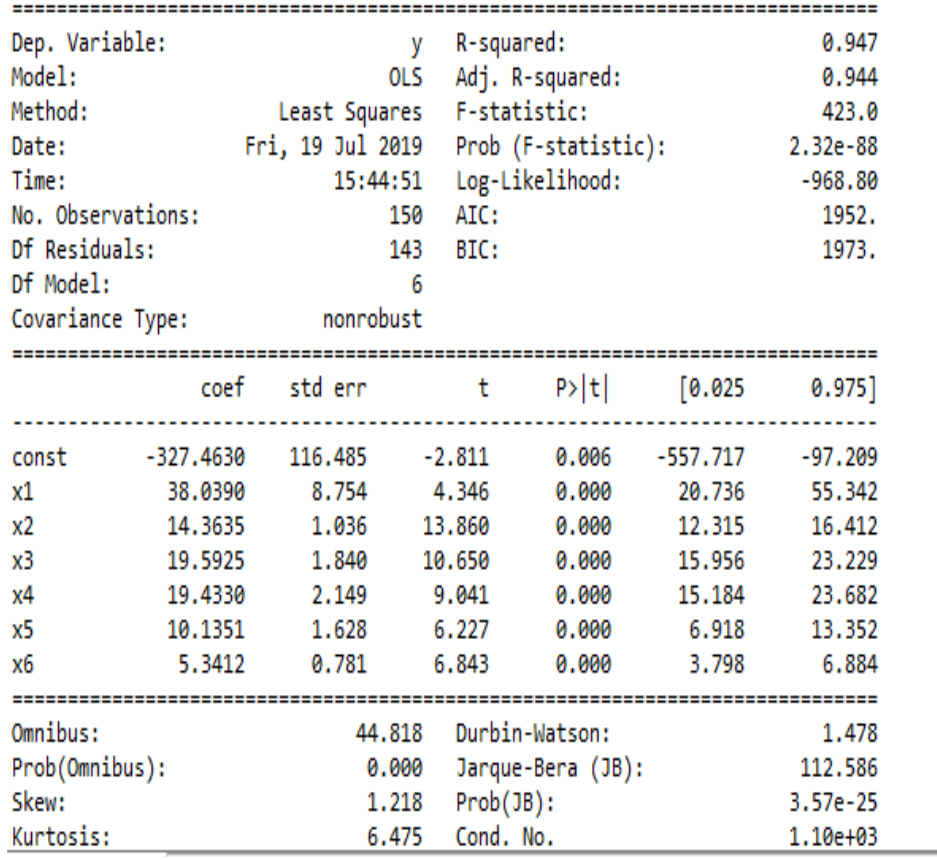

Şekil.6 Sonucu Etkileyen faktörler

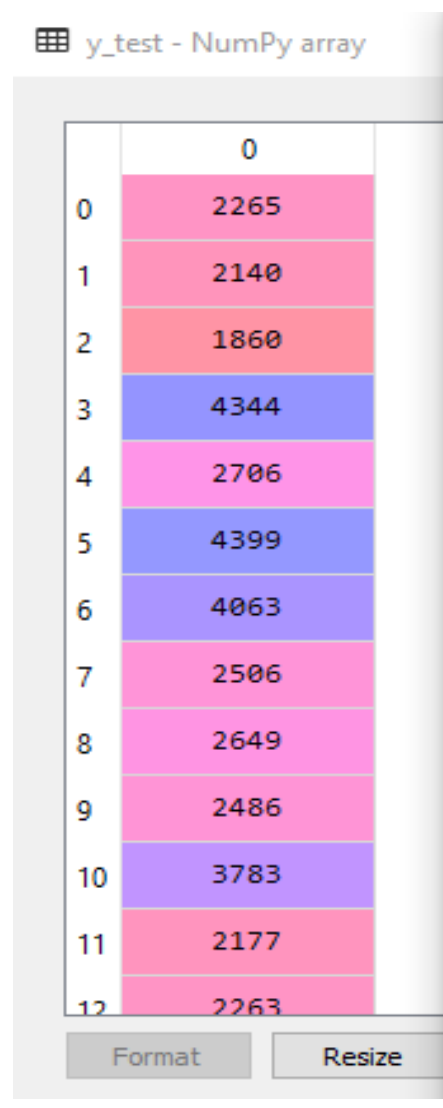

囲 y_predictions - NumPy a

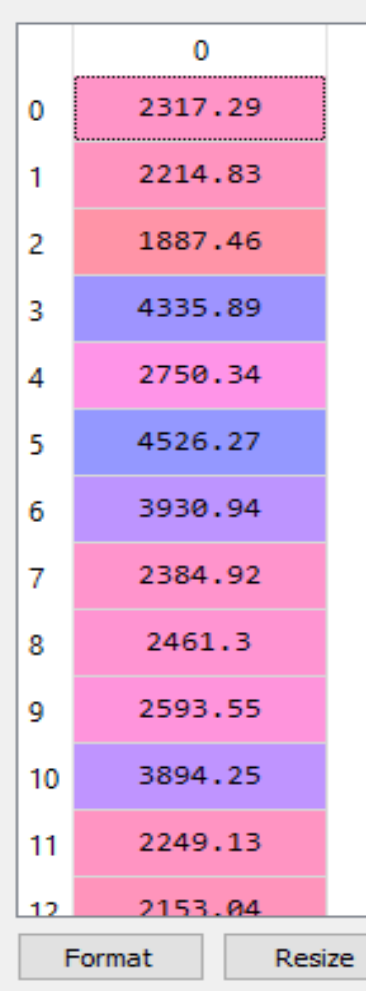

Şekil.7 Test verisi ile Sistemin tahminlerinin karşılaştırlması

Şekil 6'de sonucumuzu en çok etkileyen faktörlerin tespitini en küçük kareler yöntemiyle tespit ettik ve Şekil 6'da test verilerimiz ile modelin tahmin sonuçlarının karşılaştırması bulunmaktadır. Şekil 7'da anlaşılacağı gibi test verileri ile tahmin verileri arasındaki uyum gayet iyi görünmektedir. Doğruluk oranıda \%91,3 olarak görülmektedir. 


\section{Sonuç ve Tartışma}

Çalışmada 2018 yılı XYZ işletmesinin günlük satış cirosu, ürün çeşitleri, ekonomik satın alma gücü, gerçekleşen hava sıcaklığ1 ve haftanın günlerini sisteme girdi olarak tanıttık. Bu değerlerin \% 70 eğitim için \%30 test için kullandık. Matlab ortamında bu verilerden yapay sinir ağları yöntemiyle tahminler yaptık. Yapılan bu tahminlerde ortalama test başarı oranı ortalama \%96,662 değerine ulaşmıştır. Python programlama dilinde yaptığımız çoklu regresyon uygulamasıyla ise doğruluk oranı \%91,3 olarak gerçekleşmiştir. Regresyon yöntemiyle sonuç değişkenimize en az etki eden faktörleri belirledik bunlar haftanın günleri ve hava durumu olarak karşımıza çıtı. YSA'nın başarısı test değerlerinden anlaşılmaktadır.

Çalışmada YSA daha başarılı yöntem olarak göze çarpmaktadır. Kullandığımız veri setindeki veri çeşitliliğinin fazla olması durumunda parametreler arasındaki ilişkiyi inceleme firsatımızda olacaktır. Giriş parametlerini daha çok çeşitlendirebilirsek ve verisetinide artırabilirsek sistem başarısı daha da yukarı çıkacaktır. Maksimum talebin hangi şartlarda oluşacağınıda karar ağacı algoritmasını kullanarak da bulabiliriz.

\section{Kaynaklar}

Akdag, R. (2016). Yapay Sinir Aglari, Destek Vektör Makineleri ve Box-Jenkins Yöntemleriyle Kentsel Icmesuyu Talebi Tahmini ve Karsilastirmali Analizi. Business and Economics Research Journal, 7(1), 123-138

Başoğlu, B., ve Bulut, M. (2017). Kısa dönem elektrik talep tahminleri için yapay sinir ağları ve uzman sistemler tabanlı hibrit sistem geliştirilmesi. Journal of the Faculty of Engineering and Architecture of Gazi University, 32(2), 575-583.

Calp, M. H. (2019). İşletmeler için personel yemek talep miktarının yapay sinir ağları kullanılarak tahmin edilmesi. Politeknik dergisi. 22(3), 675-686

Chehreh, C S, James, C H, Jorjani, E, Mesroghli, S ve Bagherieh, A H, (2008). Prediction of coal grindability based on petrography, proximate and ultimate analysis using multiple regression and artificial neural network models. Fuel Processing Technology, 89,1320.

Çuhadar, M., ve Kayacan, C. (2005). Yapay Sinir Ağları Kullanılarak Konaklama İşletmelerinde Doluluk Oranı Tahmini: Türkiye'deki Konaklama İşletmeleri Üzerine Bir Deneme. Anatolia: Turizm Araştırmaları Dergisi, 16(1), 24-30.

Çuhadar, M., Güngör, İ., ve Göksu, A. (2009). Turizm Talebinin Yapay Sinir Ağlari ile Tahmini ve Zaman Serisi Yöntemleri ile Karşilaştirmali Analizi: Antalya İline Yönelik Bir Uygulama. Süleyman Demirel Üniversitesi İktisadi ve İdari Bilimler Fakültesi Dergisi, 14(1), 99-114.

Durna, M. B., "Veri Bilimi İçin Temel Python Kütüphaneleri-1: Numpy” (Erişim tarihi 2019.05.14) https://medium.com

Efendigil, T., ve Eminler, Ö. E. (2017). Havacılık Sektöründe Talep Tahmininin Önemi: Yolcu Talebi Üzerine Bir Tahmin Modeli. Journal of Yasar University, 12, 14-30

Eren, U., ve Satoğlu, Ş. I. Perakende Giyim Sektöründe Yapay Sinir Ağları ile Talep Tahmini.

Es, H. A., Kalender, F. Y., ve Hamzaçebi, C. (2014). Yapay sinir ağlari ile Türkiye net enerji talep tahmini. Gazi Üniversitesi Mühendislik-Mimarlık Fakültesi Dergisi, 29(3), 227-233

Hamzaçebi, C., ve Kutay, F. (2004). Yapay sinir ağlari ile türkiye elektrik enerjisi tüketiminin 2010 yilina kadar Tahmini. Gazi Üniversitesi Mühendislik-Mimarlık Fakültesi Dergisi, 19(3).

Karaatlı, M., Helvacıŏlu, Ö. C., Ömürbek, N., ve Tokgöz, G. (2012). Yapay sinir ağları yöntemi ile otomobil satış tahmini. Uluslararası Yönetim İktisat ve Işletme Dergisi, 8(17), 87-100.

Karaca, C., ve Karacan, H. (2016). Çoklu regresyon metoduyla elektrik tüketim talebini etkileyen faktörlerin incelenmesi. Selçuk Üniversitesi Mühendislik, Bilim ve Teknoloji Dergisi, 4(3), 182-195.

Özüdoğru, A. G., ve Görener, A. (2015). Sağl1k sektöründe talep tahmini üzerine bir uygulama. Ístanbul Ticaret Üniversitesi Sosyal Bilimleri Dergisi 27(Bahar), 37-53

Turanl, M. (2003). Turizm sektöründe talep tahmin modellemesi. İstanbul Ticaret Üniversitesi Dergisi, 3(Haziran), 1-13

Ulgen, K. E. “Makine Öğrenimi Bölüm-6 (Regresyon)” (Erişim 2019.05.14) https://medium.com/

Ulucan, Ö. G. E., ve Kızılırmak, İ. (2018). Konaklama İşletmelerinde Talep Tahmin Yöntemleri: Yapay Sinir Ağları İle İlgili Bir Araştırma. Seyahat ve Otel İşletmeciliği Dergisi, 15(1), 89-101.

Üstündağ, H., ve Sayım, I. Ş. I. (2018). Antalya Bölgesinde Otel Oda Fiyatlarının Tahmini. Journal of Travel and Hospitality Management, 15(3), 703-716.

Yongjae, K, Sehun, R, (2005). Arc sensor model using multiple-regression analysis and a neural network. ProQ. Sci. J. ,219, $431-447$.

Yucesan, M., Gul, M., ve Celik, E. (2018). A multi-method patient arrival forecasting outline for hospital emergency departments. International Journal of Healthcare Management, 1-13.

Yüceoğlu, Birol “Scikit-Learn ile Veri Analitiğine Giriş” (Erişim tarihi 2019.05.14) http://www.veridefteri.com/ 